\title{
Bioactive Glass Nanoparticles as a New Delivery System for Sustained 5-Fluorouracil Release: Characterization and Evaluation of Drug Release Mechanism
}

\author{
Abeer M. El-Kady ${ }^{1,2}$ and Mohammad M. Farag ${ }^{1,2}$ \\ ${ }^{1}$ Biomaterials Department, National Research Centre, 33 El-Bohooth Street, Dokki, Cairo 12622, Egypt \\ ${ }^{2}$ Advanced Materials and Nanotechnology Laboratory, Center of Excellence, National Research Centre, Dokki, Cairo 12622, Egypt \\ Correspondence should be addressed to Abeer M. El-Kady; abeerelkady_2000@yahoo.co.uk
}

Received 9 December 2014; Revised 5 July 2015; Accepted 9 August 2015

Academic Editor: Piaoping Yang

Copyright ( 92015 A. M. El-Kady and M. M. Farag. This is an open access article distributed under the Creative Commons Attribution License, which permits unrestricted use, distribution, and reproduction in any medium, provided the original work is properly cited.

\begin{abstract}
Bioactive glass nanoparticles were synthesized and tested for the first time as a new delivery system for sustained 5-fluorouracil (5-FU) release. They were characterized by TEM, DTA, TGA, and FT-IR. The porosity $\%$ and specific surface area of glass nanoparticles were $85.59 \%$ and $378.36 \mathrm{~m}^{2} / \mathrm{g}$, respectively. The in vitro bioactivity evaluation confirmed that bioactive glass disks prepared from these nanoparticles could induce hydroxyapatite layer over their surfaces in simulated body fluid. The in vitro drug release experiment indicated that glass nanoparticles could serve as long-term local delivery vehicles for sustained 5-FU release. The release profile of 5-FU showed an initial fast release stage followed by a second stage of slower release. The initial burst release of 5 -FU in the first day was about $23 \%\left(28.92 \mathrm{mg} \cdot \mathrm{L}^{-1}\right)$ of the total amount of loaded $5-\mathrm{FU}$, while the final cumulative percentage of the 5-FU released after 32 days was about $45.6 \%\left(57.31 \mathrm{mg} \cdot \mathrm{L}^{-1}\right)$ of the total amount of loaded 5-FU. The application of different mathematical models indicated that 5-FU was released by diffusion controlled mechanism and suggested that its release rate was dependent on glass particles dissolution, changes of surface area as well as diameter of glass particles, and concentration of loaded drug.
\end{abstract}

\section{Introduction}

Cancer is considered as a serious life threatening condition. Systematic administration of chemotherapy has been the major treatment methodology. However, the efficacy of many anticancer drugs is limited by their abilities to reach the site of therapeutic action. In most cases, a small amount of administered dose reaches the target site, while the majority of drug distributes throughout the rest of the body causing severe side effects to healthy organs. Anticancer drug such as 5-fluorouracil (5-FU) has been used to treat different types of cancer [1]. However, 5-FU has short biological half-life (8$20 \mathrm{~min}$ ) due to its rapid metabolism. In addition, it has shown sever toxic side effects due to its nonselective action against healthy cells [2]. Therefore, developing a drug delivery system that optimizes the pharmaceutical action of 5-FU, while reducing its toxic side effects, is considered a challenging task.
One approach is to use a drug carrier that can provide site specific drug delivery combined with an optimal drug release profile. Site specific delivery of drugs to the receptor site has the potential to reduce side effects against healthy organs and cells while increasing the pharmacological response of released drugs over diseased cells.

Multiple biodegradable polymeric microspheres and nanoparticles have been used as local drug delivery systems for anticancer drugs [3-7]. However, the degradation of polymers could cause sever inflammatory response due to their acidic degradation products, which might interfere with the intended therapy. In addition, these polymers were not bioactive and could not be used for bone regeneration. On the other hand, sol-gel bioactive glass is known to be bioactive and biocompatible [8-12]. Also bioactive glass is degradable, and thus no need for a second surgery to remove it from body [13]. In addition, it has the ability to induce hydroxyapatite 
layer on its surface as a result of immersion in body fluid. This layer is known to be very essential for bone regeneration in vivo [13-17]. Bioactive glass has a well documented ability to regenerate bone tissue in vivo $[13,14]$. Recently, bioactive glass nanoparticles in the system $\left(\mathrm{SiO}_{2}-\mathrm{CaO}-\mathrm{P}_{2} \mathrm{O}_{5}\right)$ have been prepared for bone engineering application [18-22] and osteomyelitis treatment [23-25]. They were highly porous with high surface areas, which could make those nanoparticles suitable as drug carriers. According to our knowledge, bioactive glass nanoparticles were not tested yet as delivery vehicles for sustained 5-fluorouracil (5-FU) release. Therefore, the main aim of this study was testing the possibility to use bioactive glass nanoparticles for sustained 5-FU delivery. These nanoparticles could be useful for localized cancer treatment. The innovative hypothesis of this application was that drug-loaded nanoparticles could provide a sustained release of therapeutic doses of 5-FU which could prevent tumor recurrence after resection. In addition, mechanism of drug release from these nanoparticles was evaluated by fitting its release profile to different mathematical models [26-28]. Those models have been used extensively in the literature to model the release profile of different types of drugs from various delivery vehicles [28-30]. They are (1) Higuchi square root of time model, which was used for modeling diffusion controlled release mechanism of a drug from a porous matrix, (2) first-order time model, which described the release of drug from a system where the release rate was concentration dependent, (3) Baker-Lonsdale model expressing the diffusion controlled release mechanism of a drug from matrices of spherical shape, and (4) cube-root Hixson-Crowell model which was used for modeling drug release profile from systems with dissolution rate limitations.

\section{Materials and Methods}

2.1. Materials. Ultra-pure tetraethyl orthosilicate (TEOS), calcium nitrate tetrahydrate $\mathrm{Ca}(\mathrm{NO})_{3} \cdot 4 \mathrm{H}_{2} \mathrm{O}$, and triethyl phosphate (TEP), purchased from Fluka (Buchs, Switzerland), were used in the synthesis of bioactive glass nanoparticles. $2 \mathrm{M}$ nitric acid and ammonia solutions were prepared from ammonia solution, 33\%, and nitric acid, 68\% (Merck, USA).

2.2. Sol-Gel Synthesis of Bioactive Glass Nanoparticles. Bioactive glass nanoparticles based on $70 \mathrm{SiO}_{2}-26 \mathrm{CaO}-4 \mathrm{P}_{2} \mathrm{O}_{5}$ (wt $\%)$ were synthesized by a modified sol-gel method [18-20, $23,24]$. In brief, TEOS was added dropwise to a mixture of distilled water, ethanol, and $2 \mathrm{M}$ nitric acid followed by stirring for $1 \mathrm{~h}$ to achieve the complete acid hydrolysis of TEOS. Thereafter, TEP and $\mathrm{Ca}\left(\mathrm{NO}_{3}\right)_{2} \cdot 4 \mathrm{H}_{2} \mathrm{O}$ were added while stirring was continued for $1 \mathrm{~h}$ after each addition; then the whole solution was placed in a conventional ultrasonic bath (working at a frequency of $50-60 \mathrm{kHz}, 100 / 200 \mathrm{~W}$ ). Meanwhile, ammonia solution (2 M) was added dropwise to the mixture while continuous agitation by a mechanical stirring was carried out to prevent the formation of a bulk gel. The solution was completely transformed to a white gel in few minutes. Finally, the prepared gel was dried at $75^{\circ} \mathrm{C}$ for 2 days in a drying oven and then it was subjected to heat treatment at $700^{\circ} \mathrm{C}$ for $3 \mathrm{~h}$ with rate of $3^{\circ} \mathrm{C} / \mathrm{min}$ to stabilize and convert such gel to glass.

2.3. Characterization. TEM (JEM2010, Japan) working at $200 \mathrm{Kv}$ was used to analyze the morphology and particle sizes of the bioactive glass nanoparticles. Fourier transformer infrared spectrophotometer (FT-IR) (model FT/IR-6100 type A) was used to study the glass structure. The infrared spectrum of the prepared glass was recorded in a wave number range of $400-4000 \mathrm{~cm}^{-1}$. The temperature used for the glass stabilization and converting the dry gel to glass powder was determined by thermal analysis. Thermogravimetric analysis (TGA) and differential thermal analysis (DTA) were carried out for the dried gel using a computerized 7 series USA Perkin Elmer thermal analysis system. Scans were performed in an air atmosphere at a temperature range of $50-1000^{\circ} \mathrm{C}$ and a rate of $10^{\circ} \mathrm{C} \mathrm{min}^{-1}$, using aluminum oxide powder as a reference. The specific surface area, average pore diameter, and total pore volume of the glass nanoparticles were measured with a high-speed gas sorption analyzer (NOVA 2000 series, Chromatic, UK) at $77 \mathrm{~K}$. The porosity \% of the glass was determined using the mercury intrusion porosimetry technique (19321, Micrometric, USA).

2.4. In Vitro Bioactivity Evaluation. Disks of glass powder were used to evaluate the in vitro bioactivity of sample in the simulated body fluid (SBF) [31]. The glass powder was shaped into disks by uniaxial compression, under $2 \mathrm{MPa}$ pressure. Such prepared disks were immersed in SBF at $37^{\circ} \mathrm{C}$ for two weeks. The SBF had a composition and an ionic concentration almost equal to human plasma. The solution was buffered at $\mathrm{pH} 7.4$ with tris(hydroxymethyl)aminomethane and $1 \mathrm{M}$ $\mathrm{HCl}$ at $37^{\circ} \mathrm{C}$ [31]. The precipitation of apatite layer on the surfaces of glass disks was verified using scanning electron microscope coupled with energy dispersive X-ray analysis (JEOL JXA-840A, Electron probe microanalyzer, Japan) and thin-film X-ray analysis (TF-XRD) (Panalytical, X'Pert Pro, The Netherlands), employing Ni-filtered $\mathrm{Cu} \mathrm{K} \alpha$ irradiation at $45 \mathrm{Kv}$ and $40 \mathrm{~mA}$.

\subsection{Nanoparticles Surveying as a Delivery System for 5-Fluorouracil (5-FU)}

2.5.1. Loading of Drugs onto Glass Nanoparticles. The glass powder was loaded with 5-fluorouracil (5-FU), where $0.3 \mathrm{~g}$ of glass powder was immersed, for 2 days, in $10 \mathrm{~mL}$ of drug solution $\left(250 \mathrm{~mL} \cdot \mathrm{L}^{-1}\right)$ as illustrated in Figure 1 . Then glass powder was separated from the solution by centrifuge and the uptake of drug by glass was calculated as the difference in drug concentration in the solution before and after sample immersion. 5-FU concentrations were determined using an UV spectrophotometer at $\lambda=266 \mathrm{~nm}$.

2.5.2. Determination of the Cumulative Drug Concentration Released from the Glass Nanoparticles. To study the release profile of drug from glass, each sample loaded with 5-FU was immersed in $10 \mathrm{~mL}$ of Tris buffer solution $(\mathrm{pH}=7.4)$. At predetermined time, $2 \mathrm{~mL}$ of solution was withdrawn 


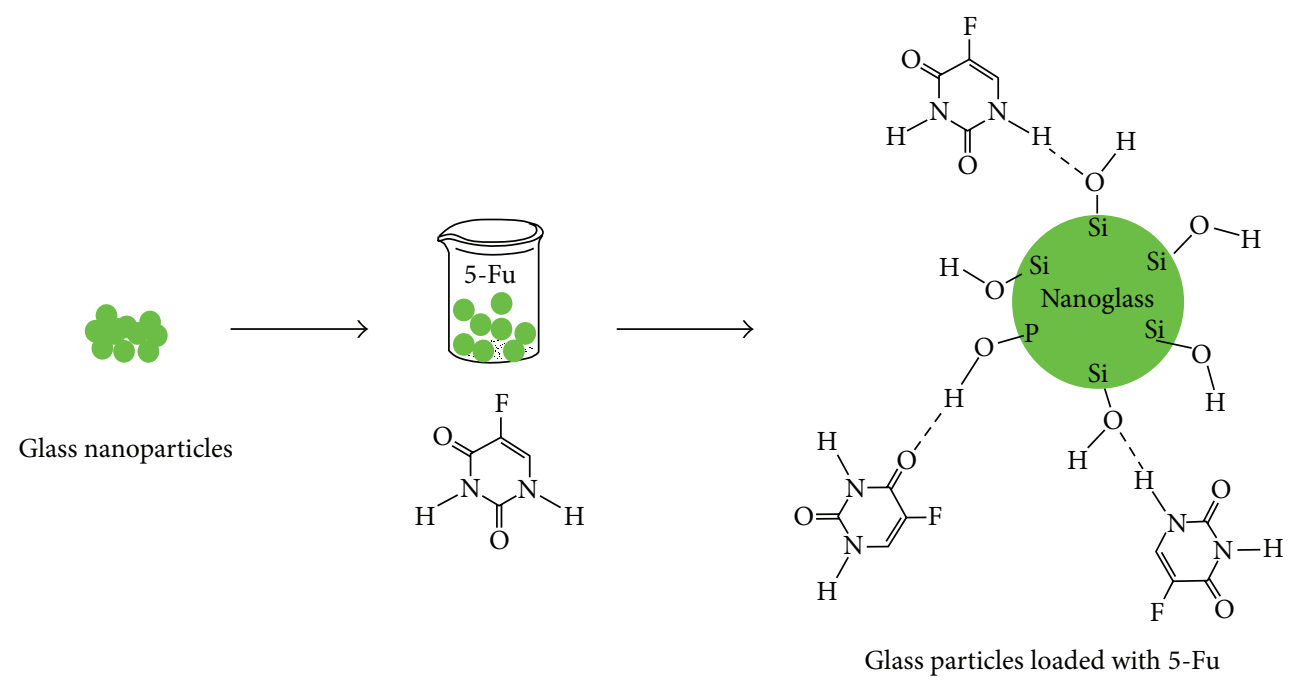

FIGURE 1: Nanoparticles surveying as a delivery system for 5-fluorouracil (5-FU).

and replaced by fresh $2 \mathrm{~mL}$ Tris buffer solution. The concentration of the released drug was measured using UV spectrophotometer at $\lambda=266 \mathrm{~nm}$. The concentration of drug was calculated from standard curve. Solutions of known drug concentrations were prepared and their corresponding absorptions at $\lambda=266 \mathrm{~nm}$ were measured. A curve was constructed between the known drug concentrations and their corresponding absorptions. From that curve, the unknown drug concentrations in the released samples were determined.

2.5.3. Analysis of Drug Releasing Kinetics. The mechanism of drug release from the nanoparticles was evaluated by fitting the release data to the following mathematical models [2628]:

(1) Higuchi square root of time model:

$$
Q=k_{1} t^{0.5}
$$

(2) first-order time model:

$$
\ln (1-Q)=-k_{2} t
$$

(3) Baker-Lonsdale model:

$$
\frac{3}{2}\left[1-(1-Q)^{2 / 3}\right]-Q=k_{3} t
$$

(4) cube-root Hixson-Crowell model:

$$
(1-Q)^{1 / 3}=-k_{4} t
$$

where $Q$ is the fraction of drug released at time $t$, while $k_{1}, k_{2}, k_{3}$, and $k_{4}$ are the release rate constants, which were obtained by fitting the drug release profile to (1), (2), (3), and (4), respectively. Then linear regression analysis of the dissolution data was carried out using Microcal (MT) origin version 6 , and a straight line was fitted through the

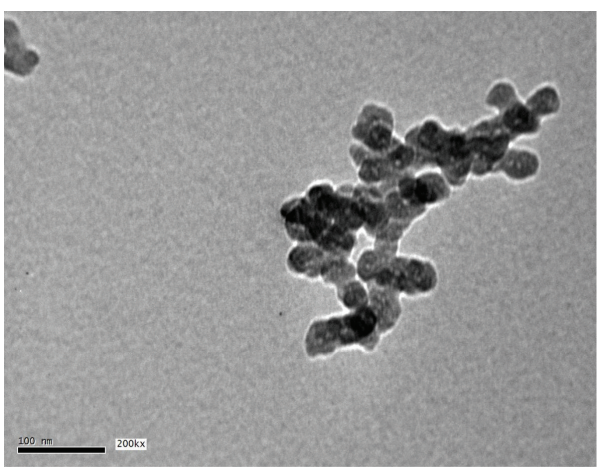

FIGURE 2: TEM micrograph of the prepared glass powder.

data. The slope of that line gave the release rate constant. In addition, correlation coefficient $\left(R_{C}\right)$ was determined, which is a statistical measure of how well the regression line approximates the real dissolution data.

2.5.4. Statistical Analysis. Throughout this work, all data were expressed as the mean \pm standard deviation (SD) for $n=3$ and were analyzed using standard analysis of Student's $t$-test. The level of significance is set at $p<0.05$.

\section{Results and Discussions}

3.1. TEM. Figure 2 shows the TEM micrograph of the prepared glass powder. Agglomerated spherical shaped nanoparticles less than $100 \mathrm{~nm}$ in size were seen in the figure.

3.2. Thermal Analysis. Thermogravimetric analysis (TGA) and differential thermal analysis (DTA) curves for the prepared dry gel are shown in Figure 3(a). The DTA curve showed a large endothermic peak centered around $67^{\circ} \mathrm{C}$, which was due to the elimination of residual alcohol and physically adsorbed humidity water from the pores of the 


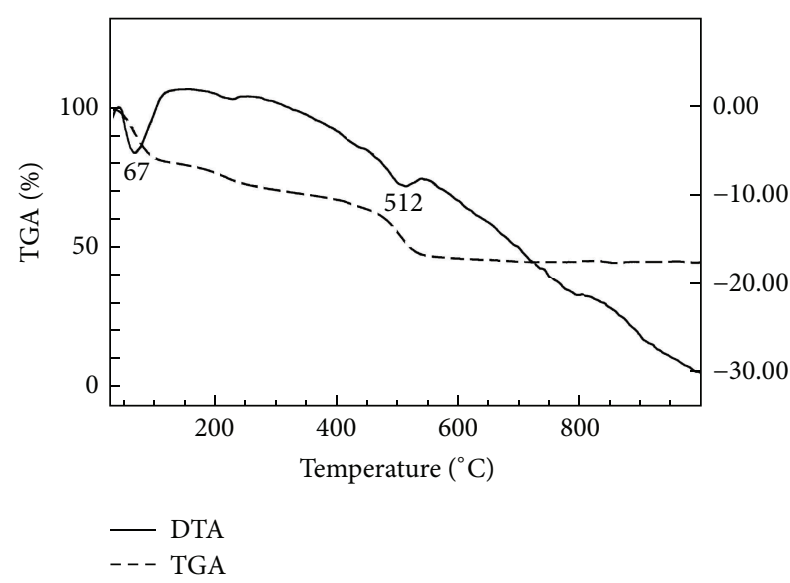

(a)

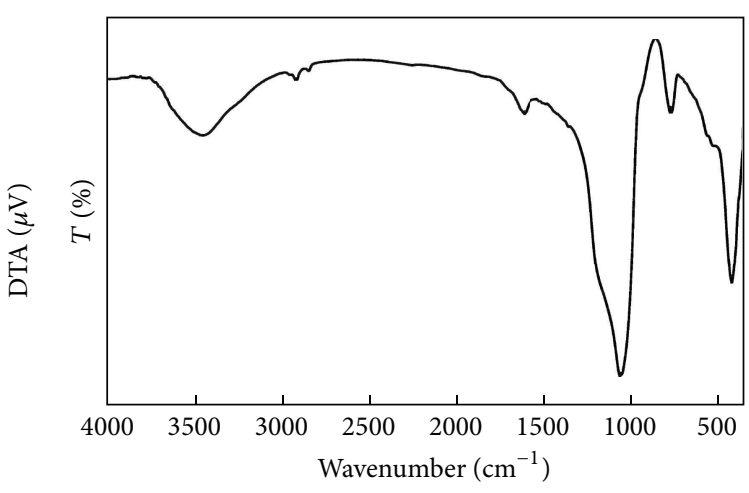

(b)

FIGURE 3: Thermogravimetric analysis (TGA) and differential thermal analysis (DTA) curves for the prepared dry gel (a), as well as the FT-IR spectrum of glass nanoparticles (b).

gel [32]. This was reflected by the first weight loss $(27.2 \%)$ shown by TGA curve. The second endothermic peak centered around $512^{\circ} \mathrm{C}$ on the DTA curve was due to the decomposition of nitrates leading to the second weight loss $(25.7 \%)$ seen in the TGA curve [20]. The results confirmed that all residuals were removed before $700^{\circ} \mathrm{C}$.

3.3. FT-IR. FT-IR spectrum of bioactive glass nanoparticles is shown in Figure 3(b). As shown in the figure, a strong band centered at $1099 \mathrm{~cm}^{-1}$ was corresponded to $\mathrm{Si}-\mathrm{O}-\mathrm{Si}$ asymmetric stretching vibration. Furthermore, a small band located at $797 \mathrm{~cm}^{-1}$ was referred to the $\mathrm{Si}-\mathrm{O}-\mathrm{Si}$ symmetric stretching vibration. Moreover, a band centered at $474 \mathrm{~cm}^{-1}$ was corresponded to the [Si-O-Si] bending mode $[33,34]$. Meanwhile, a broad band located at about $3451 \mathrm{~cm}^{-1}$ was attributed to hydroxyl group $(-\mathrm{OH})$ or silanol group $(\mathrm{Si}-\mathrm{OH})$ vibrations [35-38].

3.4. Textural Analysis. The porosity and surface area of any material are the mean characteristic textural features that determined its use as drug delivery system. Textural analysis obtained in this study showed that glass powder was characterized by high porous structure and high specific surface area, whereas the porosity $\%$ of such glass nanoparticles was $85.59 \%$ and the specific surface area was $378.36 \mathrm{~m}^{2} / \mathrm{g}$. The $\mathrm{N}_{2}$ adsorption-desorption isotherm curve of glass nanoparticles is shown in Figure 4. From the figure it could be detected that such curve was corresponded to the type IV isotherm according to the IUPAC classification [39]. The characteristic hysteresis loop of that isotherm was clearly shown, where desorption and absorption branches did not follow the same path at relatively high $P / P_{0}$ values. This behavior clearly indicated the presence of mesopores in the sample. The pore size distribution was obtained from the desorption branch of the isotherm following the $\mathrm{BJH}$ method and is shown by Figure 5. It could be clearly seen that bioactive glass

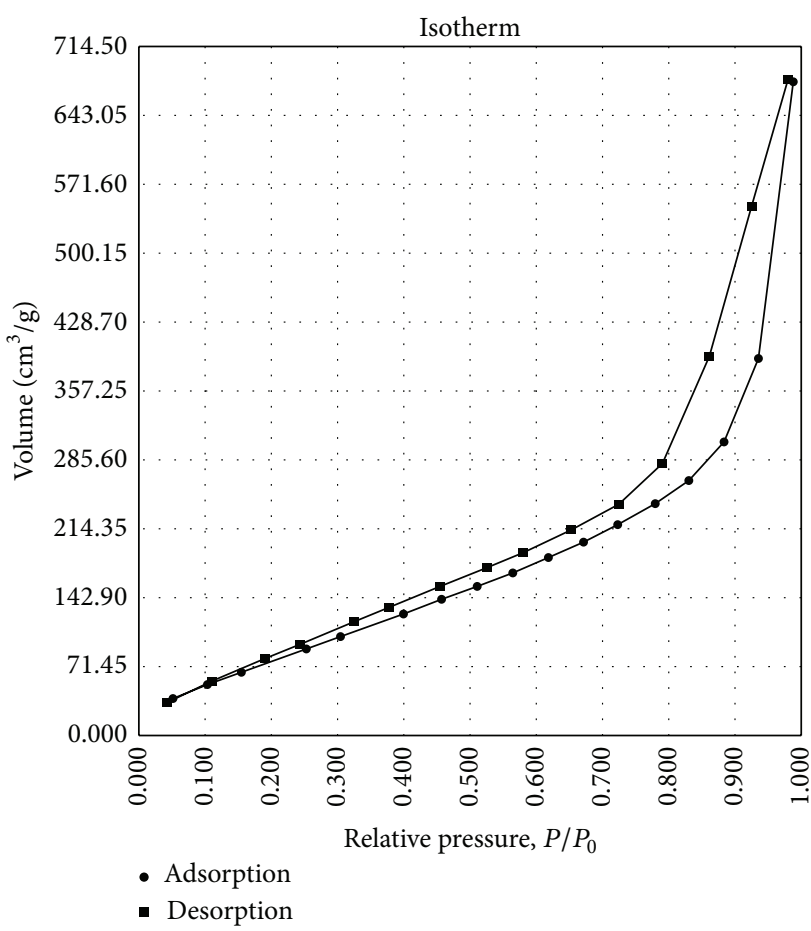

FIGURE 4: The $\mathrm{N}_{2}$ adsorption-desorption isotherm of glass nanoparticles.

nanoparticles had a broad pore size distribution and most of pores were in the mesorange $(2-50 \mathrm{~nm})$. The average pore diameter as determined by $\mathrm{BJH}$ method and total pore volume were $2.14 \mathrm{~nm}$ and $0.1562 \mathrm{~cm}^{3} / \mathrm{g}$, respectively. The porous nature of glass nanoparticles could be attributed to water and ethanol evaporation as well as nitrate decomposition during the stabilization process. 


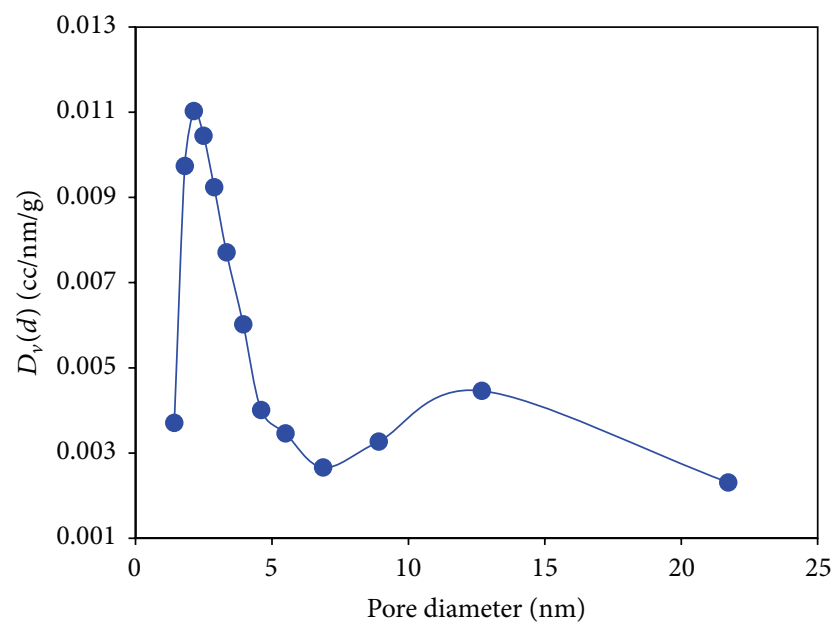

FIgURE 5: The pore size distribution curve obtained from the desorption branch of the isotherm.

3.5. In Vitro Bioactivity Evaluation. Figure 6 shows the surfaces of glass disks after their immersion in simulated body fluid for different time periods (1, 3, and 7 days). The nucleation and growth of spherical particles over the surfaces of glass disks were clearly seen. These particles grew in size and increased in number as the time of immersion in SBF was increased. EDX analysis of these spherical particles indicated that they were carbonated hydroxyapatite with $\mathrm{Ca} / \mathrm{P}$ atomic ratio of 1.68. In addition, thin film X-ray analysis confirmed that the surface of glass disk was covered with apatite layer after one week of immersion in SBF (Figure 7). Typical crystalline diffraction pattern of hydroxyapatite (matching with ICSD card number 03-0747) could be clearly seen. The reaction mechanism of apatite formation on the glass surface was explained by different studies [9, 40]. They included the following stages: (1) rapid exchange of network modifier ions from glass with $\mathrm{H}^{+}$or $\mathrm{H}_{3} \mathrm{O}^{+}$in solution, (2) loss of soluble silica as $\mathrm{Si}(\mathrm{OH})_{4}$ to the solution and formation of $\mathrm{Si}-\mathrm{OH}$ groups at the glass/solution interface, (3) condensation and repolymerization of surface silanols and formation of $\mathrm{SiO}_{2}$-rich layer on the glass surface, (4) migration of $\mathrm{Ca}^{2+}$ and $\mathrm{PO}_{4}{ }^{3-}$ groups to the glass surface through the $\mathrm{SiO}_{2}$-rich layer leading to the formation and the eventual growth of an amorphous $\mathrm{CaO}-\mathrm{P}_{2} \mathrm{O}_{5}$-rich film by attracting soluble calcium and phosphorous ions from solution, and (5) crystallization of this amorphous film by incorporation of $\mathrm{OH}^{-}$and $\mathrm{CO}_{3}{ }^{2-}$ anions from solution to form carbonated hydroxyapatite.

\subsection{Nanoparticles Surveying as a Delivery System for 5-Fluorouracil (5-FU)}

3.6.1. Loading of Drugs onto Glass Nanoparticles. The amount of loaded 5-FU onto the glass nanoparticles was $125.75 \mathrm{mg} \cdot \mathrm{L}^{-1}$, which was $50.3 \%$ of the total amount of $5-\mathrm{Fu}$ used in loading stage $\left(250 \mathrm{mg} \cdot \mathrm{L}^{-1}\right)$. Results suggested that 5 -FU was successfully loaded onto glass nanoparticles. This was attributed to the presence of $\mathrm{SiO}_{2}$ and $\mathrm{P}_{2} \mathrm{O}_{5}$ oxides as the main components of the glass structure. Those oxides were known to form $\mathrm{SiOH}$ and $\mathrm{POH}$ groups upon hydrolysis $[32,33,40]$. Such groups could form hydrogen bonding with drug molecules (see Figure 1) and hence improved drug binding to glass nanoparticles. In addition the prepared glass nanoparticles had a highly porous structure with high surface area which could facilitate the diffusion of drug solution into the interior structure of glass nanoparticles during loading stage. Moreover, glass nanoparticles could host drug molecules inside their pores and act as reservoirs for these molecules.

3.6.2. In Vitro Drug Release Profile. Sustained drug release from a delivery device is achieved when there is an initial release of drug sufficient to provide a therapeutic dose immediately after the implantation of delivery device followed by a gradual release of drug over an extended period of time. Figure 8 (a) shows the cumulative concentration of 5$\mathrm{Fu}$ released from sample as a function of immersion time, while Figure 8(b) shows the cumulative percentage of drug released from sample as a function of time. As shown from both figures, the release profile of 5-FU from glass nanoparticles had two stages: an initial fast release stage followed by a second stage of slower release. Therefore a sustained drug delivery profile was achieved by using glass nanoparticles as delivery vehicle for 5-FU in this study. The transition to the second stage of release profile occurred at $24 \mathrm{~h}$ and continued till the end of releasing period ( 32 days). The initial burst release could be explained by the fast release of drug molecules attached to the surfaces of glass nanoparticles. On the other hand, the slower subsequent release was due to the slow diffusion of drug molecules hosted inside the porous structure of glass nanoparticles. This slower subsequent release continued throughout the rest of releasing period and up to 32 days $(768 \mathrm{~h})$. The initial burst release of 5 -FU in the first days was about $23 \%$ of the total amount of loaded 5-FU and the final cumulative percentage of the 5-FU released after 32 days was about $45.6 \%$ of the total amount of loaded 5-FU, which were 28.92 and $57.31 \mathrm{mg} \cdot \mathrm{L}^{-1}$, respectively. This revealed that at the end of drug releasing experiment (32 days), glass nanoparticles were still loaded with $54.4 \%$ of the total amount of loaded 5-FU $\left(68.44 \mathrm{mg} \cdot \mathrm{L}^{-1}\right)$ and hence, they have the ability to provide sustained drug doses for more than 32 days. The in vitro drug release experiment indicated that glass nanoparticles could serve as drug delivery system for sustained 5-FU release for long-term treatment. These nanoparticles could be used for localized cancer treatment. The initial burst release of 5-FU at the surgical site could kill the rest of tumor cells. These cells might be left after surgery. On the other hand, the long-term sustained release of drug could effectively eliminate the problem of cancer recurrence after resection.

Previously, calcium phosphate granules were developed and used as a 5-FU delivery system. The reported results revealed that 5-FU was completely released from those granules in two days [41]. In addition, alginate based microparticles were prepared for sustained release of 5-FU. The effect of chitosan reinforcement on the drug release behavior from alginate based microparticles was also investigated. 

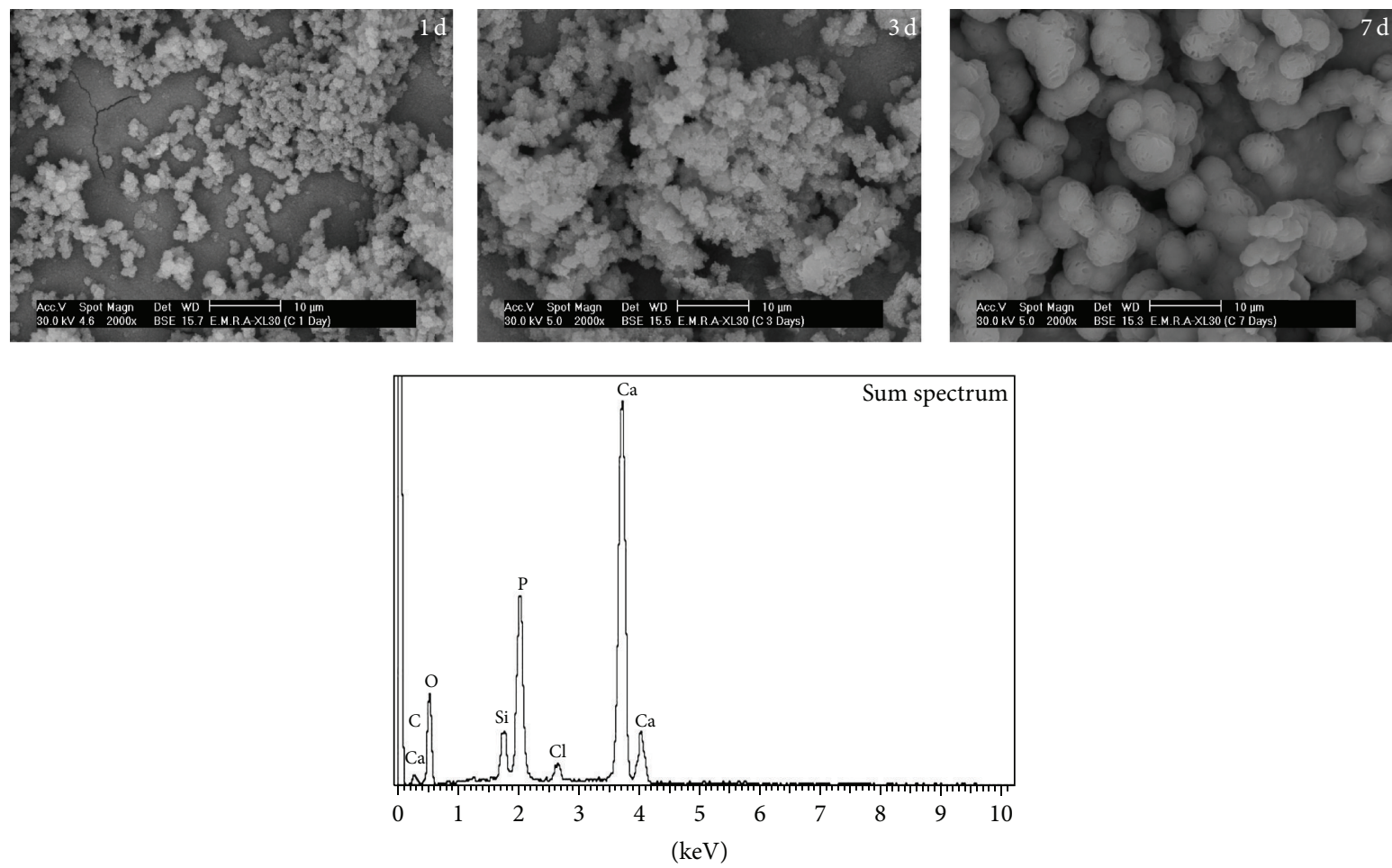

Full scale 942 cts cursor: 0.000

FIGURE 6: SEM photos of surfaces of glass disks after their immersion in simulated body fluid for different time periods (1, 3, and 7 days). The EDX analysis of surface of glass disk immersed for one week in SBF is also shown.

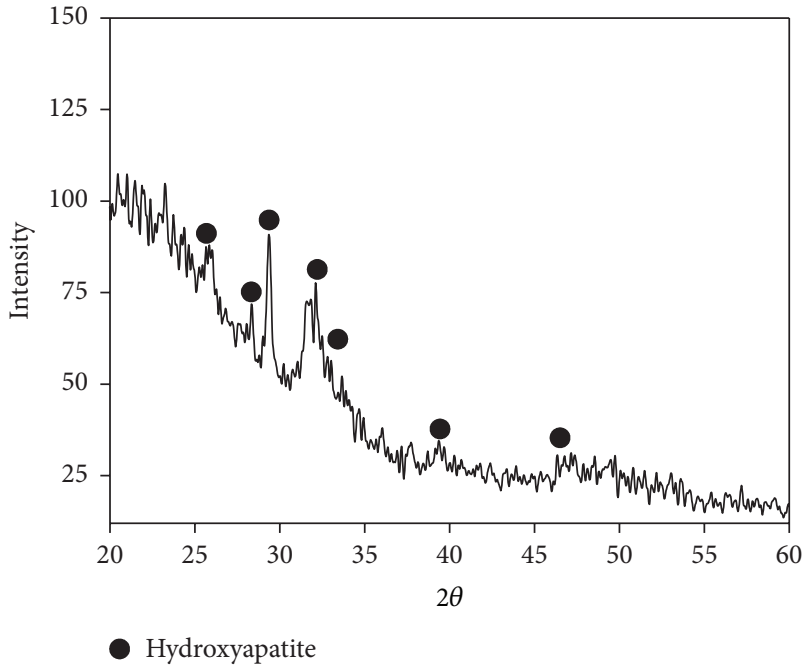

Figure 7: Thin film X-ray analysis of the surface of glass disk after one week of immersion in SBF.

The results revealed that 5-FU was released from chitosanreinforced alginate microparticles at a much slower rate as compared with unreinforced microparticles during the initial release stage. However, both types of microparticles released more than $80 \%$ of their cargo in less than $80 \mathrm{~h}$, that is, less than four days [42]. Moreover, chitosan-coated magnetic nanoparticles (CS MNPs) were prepared as carriers of 5-FU through a reverse microemulsion method [43]. The release behavior of 5-FU from CS MNPs showed that more than $80 \%$ of 5 -FU was released in $80 \mathrm{~h}$, that is, less than 4 days [43]. Furthermore, poly(acrylamidemethylmethacrylate) copolymeric core-shell microspheres crosslinked with $\mathrm{N}, \mathrm{N}$-methylenebisacrylamide were synthesized by free radical emulsion polymerization using varying amounts of acrylamide (AAm), methylmethacrylate (MMA), and N,N-methylenebisacrylamide (NNMBA) [44]. 5-FU was loaded into those microspheres during in situ polymerization (method-I) as well as by the adsorption technique (methodII). The in vitro drug release experiment indicated that release kinetics was dependent upon copolymer composition, amount of cross-linking agent, and amount of 5-FU present in the microspheres. Prolonged and controlled release of 5-FU was achieved when drug was loaded by method-I compared to by method-II. However, all the prepared microspheres released more than $80 \%$ of loaded drug in less than two days whatever the method used for drug loading [44]. Recently, $\mathrm{ZnAl}$ hydrotalcite-like nanoparticles have been loaded with 5 -FU. The release of drug from those nanoparticles was evaluated in different media. Results showed that there was a rapid and burst release during the first hour followed by a slower release of the drug which reached equilibrium in less than 5 hours [45]. Also, dual drug delivery of 5FU and methotrexate (MTX) through random copolymeric nanomicelles of PLGA and polyethylenimine was carried out. 


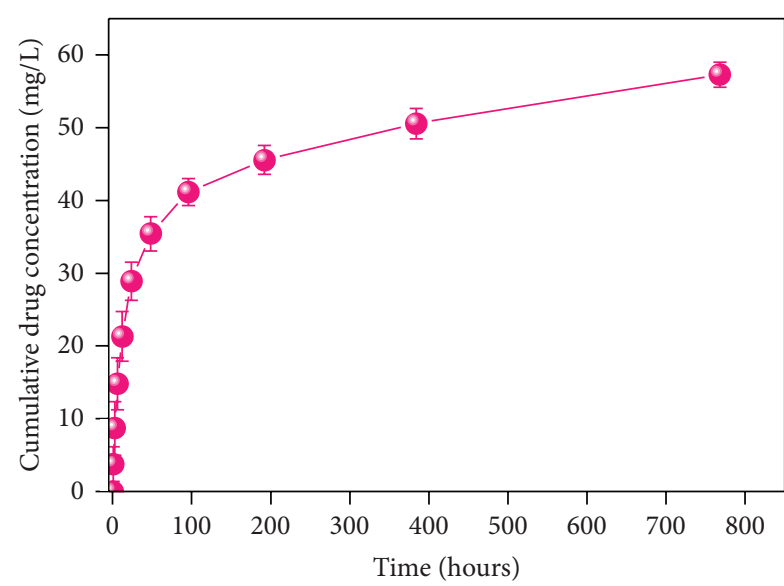

(a)

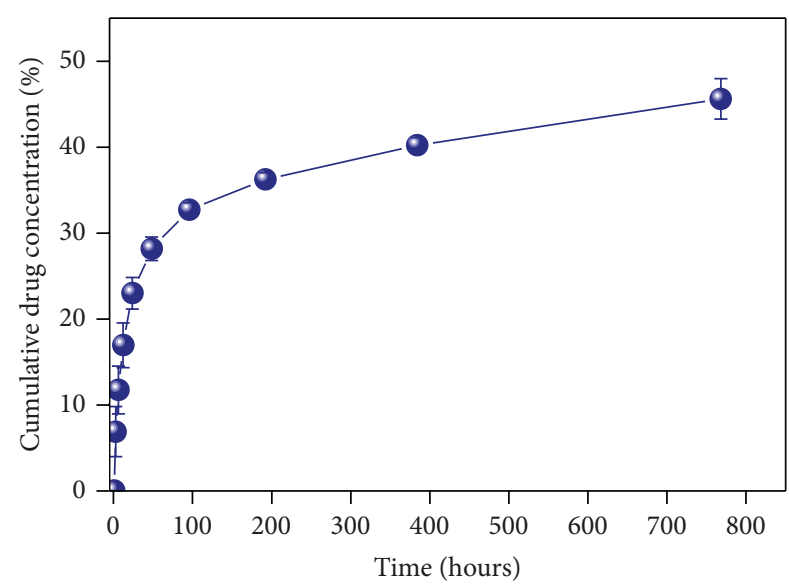

(b)

FIGURE 8: Cumulative concentration of 5-fluorouracil released from sample as a function of immersion time (a) and cumulative percentage of drug released from sample as a function of time (b).

The release profile indicated their controlled release from those nanomicelles. However, more than $75 \%$ of loaded 5 -FU was released in less than 17 hours [46].

Comparing between bioactive glass nanoparticles used in this study and the previously mentioned delivery systems indicated the superiority of glass nanoparticles as 5-FU delivery system. Result of this work demonstrated that glass nanoparticles were still loaded with $54.4 \%$ of $5-\mathrm{FU}$ at the end of release experiment (32 days) and hence, they have the ability to provide sustained drug doses for more than 32 days, which was fare more timing than those reported by the previously mentioned systems.

3.6.3. Analysis of Drug Releasing Kinetics. To study the mechanism of drug release from bioactive glass nanoparticles, the 5-FU release profile was first fitted to Higuchi square root of time model. This model has been used to express the release of drug from a porous carrier as diffusion controlled process based on Fickian diffusion and as a square root of time dependent process. The application of the Higuchi model to both stages of 5-FU release profile from glass nanoparticles is shown in Figure 9. Using the Higuchi equation, regression analysis was performed for each stage of the release profile. Correlation coefficients $\left(R_{C}\right)$ were obtained for stages one and two, and they were $\mathbf{0 . 9 8 1}$ and $\mathbf{0 . 9 6 9}$, respectively (see Table 1 ). These high correlation coefficients ( $R_{C}$ values nearly to unity) revealed that $5-\mathrm{FU}$ was released by diffusion controlled mechanism and that its release profile as well as release rate during each stage could be expressed and predicted by Higuchi equation. It was noticed that the release rate of 5 -FU was higher during stage one $\left(51.8 \times 10^{-3} \mathrm{~h}^{-0.5}\right)$ than stage two $\left(9.2 \times 10^{-3} \mathrm{~h}^{-0.5}\right)$. The higher release rate during stage one was attributed to the fast release of drug molecules attached to the surfaces of glass nanoparticles. On the other hand, the slower release rate during stage two was due to the slow diffusion of drug molecules hosted inside the porous structure of glass nanoparticles. In addition to the Higuchi model, other mathematical models such as
Baker-Lonsdale model, Hixson-Crowell cube-root model, and first-order model were used to model both stages of 5FU release profile from nanoparticles as shown in Figures 10,11 , and 12 , respectively. The correlation coefficients $\left(R_{C}\right)$ and the release rate constants were obtained by applying these mathematical models and are given in Table 1.

It was important to realize that, during stage one, the correlation coefficient was higher in the case of applying Baker-Lonsdale model $\left(R_{C}=0.998\right)$ than in the case of applying Higuchi model $\left(R_{C}=0.981\right)$. These results suggested that, throughout stage one, the Baker-Lonsdale model which described diffusion controlled drug release from spherical shape sample was more suitable for describing 5-FU release profile and calculating its release rate from glass nanoparticles than the Higuchi model. The release rates obtained by applying Baker-Lonsdale model during stages one and two were $0.42 \times 10^{-3}$ and $0.04 \times 10^{-3} \mathrm{~h}^{-1}$, respectively. Moreover, stage one and stage two of 5 -FU release profile displayed good fitting with Hixson-Crowell cube-root model (Figure 11). The correlation coefficients $\left(R_{C}\right)$ obtained for stage one and two were 0.951 and 0.923 , respectively. These high values of correlation coefficients conferred that the drug release profile from nanoparticles was dependent on glass dissolution and changes of surface area as well as diameter of the particles during dissolution. In addition, the 5-FU release rates obtained by applying Hixson-Crowell cube-root model on the release data during stages one and two were $3.5 \times$ $10^{-3}$ and $0.12 \times 10^{-3} \mathrm{~h}^{-1}$, respectively. Finally, the in vitro release profile of 5-FU from glass nanoparticles was found to follow the first-order model during stage one and stage two as the correlation coefficients $\left(R_{C}\right)$ were 0.955 and 0.929 , respectively, which indicated that the release rate of $5-\mathrm{FU}$ from glass nanoparticles during both stages was dependent on concentration of loaded drug used in the loading stage and suggested that the release rate of 5-FU could be modulated according to the patient need by changing drug concentration during loading stage. The release rates during stage one and 


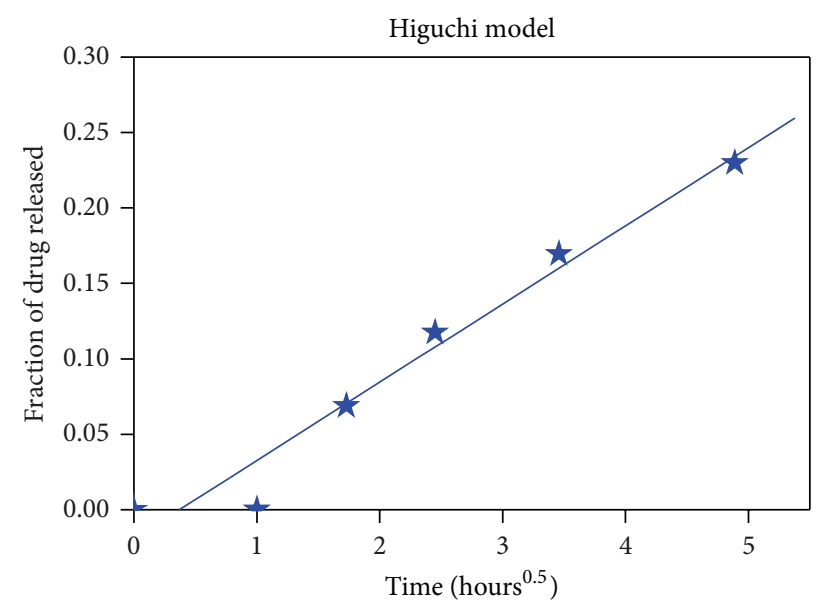

$\star$ Stage 1 $(0-24 \mathrm{~h})$

— Linear fitting of stage 1

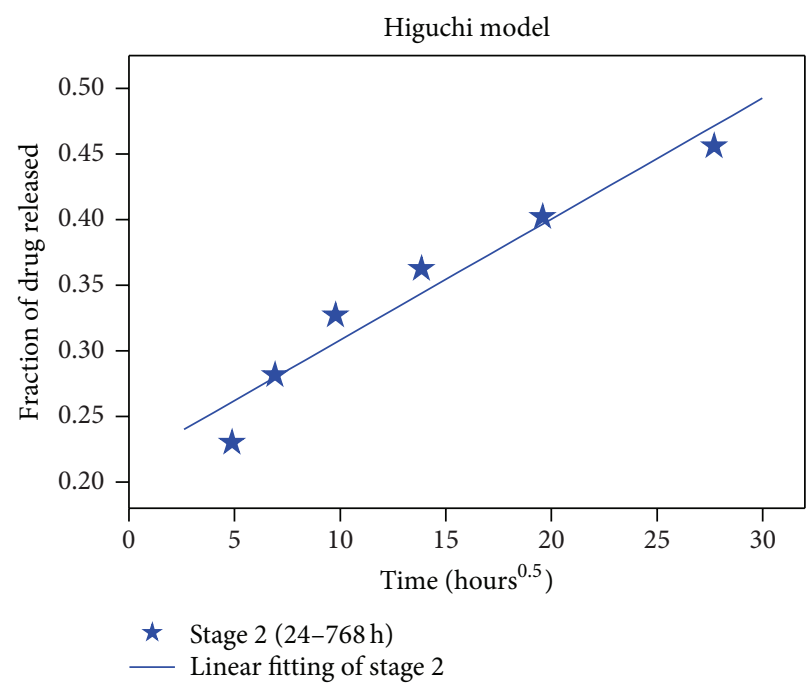

- Linear fitting of stage 2

FIGURE 9: Application of the Higuchi model to both stages of 5-FU release profile from glass nanoparticles.

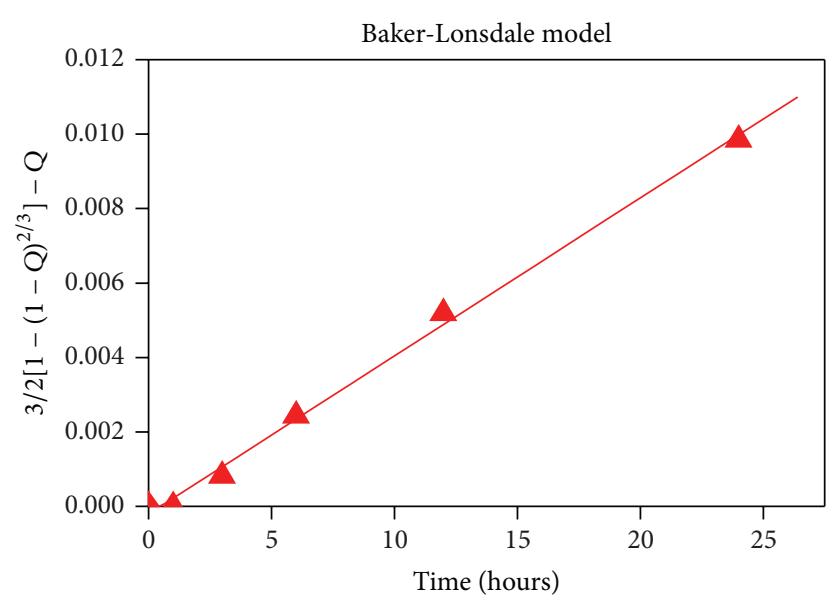

A Stage $1(0-24 \mathrm{~h})$

L Linear fitting of stage 1

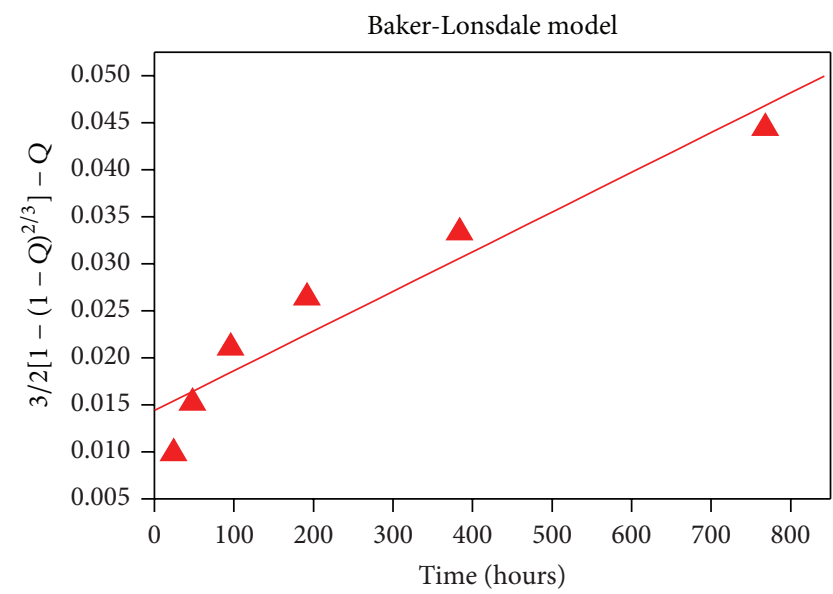

- Stage 2 (24-768h)

L Linear fitting of stage 2

FIGURE 10: Application of the Baker-Lonsdale model to both stages of 5-FU release profile from glass nanoparticles.

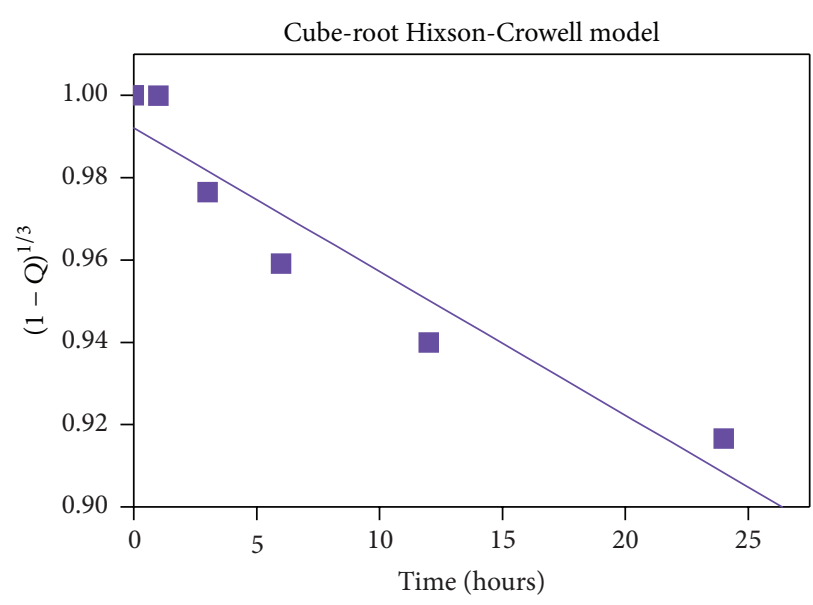

- Stage $1(0-24 \mathrm{~h})$

- Linear fitting of stage 1

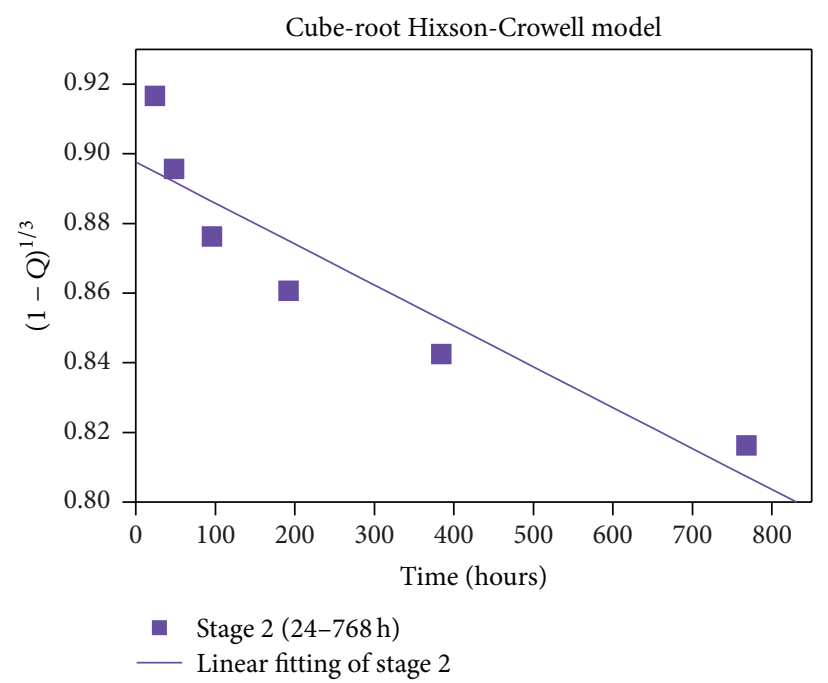

FIGURE 11: Application of the Hixson-Crowell cube-root model to both stages of 5-FU release profile from glass nanoparticles. 
TABle 1: The correlation coefficients $\left(R_{C}\right)$ and release rate constants obtained by applying different mathematical models.

\begin{tabular}{lcccc}
\hline \multirow{2}{*}{ Mathematical models } & \multicolumn{2}{c}{ Stage 1 $(0-24 \mathrm{~h})$} & \multicolumn{2}{c}{ Stage 2(24h-768h) } \\
& Correlation coefficient $\left(R_{C}\right)$ & Release rate constant & Correlation coefficient $\left(R_{C}\right)$ & Release rate constant \\
\hline Higuchi & $\mathbf{0 . 9 8 1}$ & $k_{1}=51.8 \times 10^{-3} \mathrm{~h}^{-0.5}$ & $\mathbf{0 . 9 6 9}$ & $k_{1}=9.2 \times 10^{-3} \mathrm{~h}^{-0.5}$ \\
First-order & 0.955 & $k_{2}=10.95 \times 10^{-3} \mathrm{~h}^{-1}$ & 0.929 & $k_{2}=0.41 \times 10^{-3} \mathrm{~h}^{-1}$ \\
Baker-Lonsdale & 0.998 & $k_{3}=0.42 \times 10^{-3} \mathrm{~h}^{-1}$ & 0.956 & $k_{3}=0.04 \times 10^{-3} \mathrm{~h}^{-1}$ \\
Hixson-Crowell & 0.951 & $k_{4}=3.5 \times 10^{-3} \mathrm{~h}^{-1}$ & 0.923 & $k_{4}=0.12 \times 10^{-3} \mathrm{~h}^{-1}$ \\
\hline
\end{tabular}
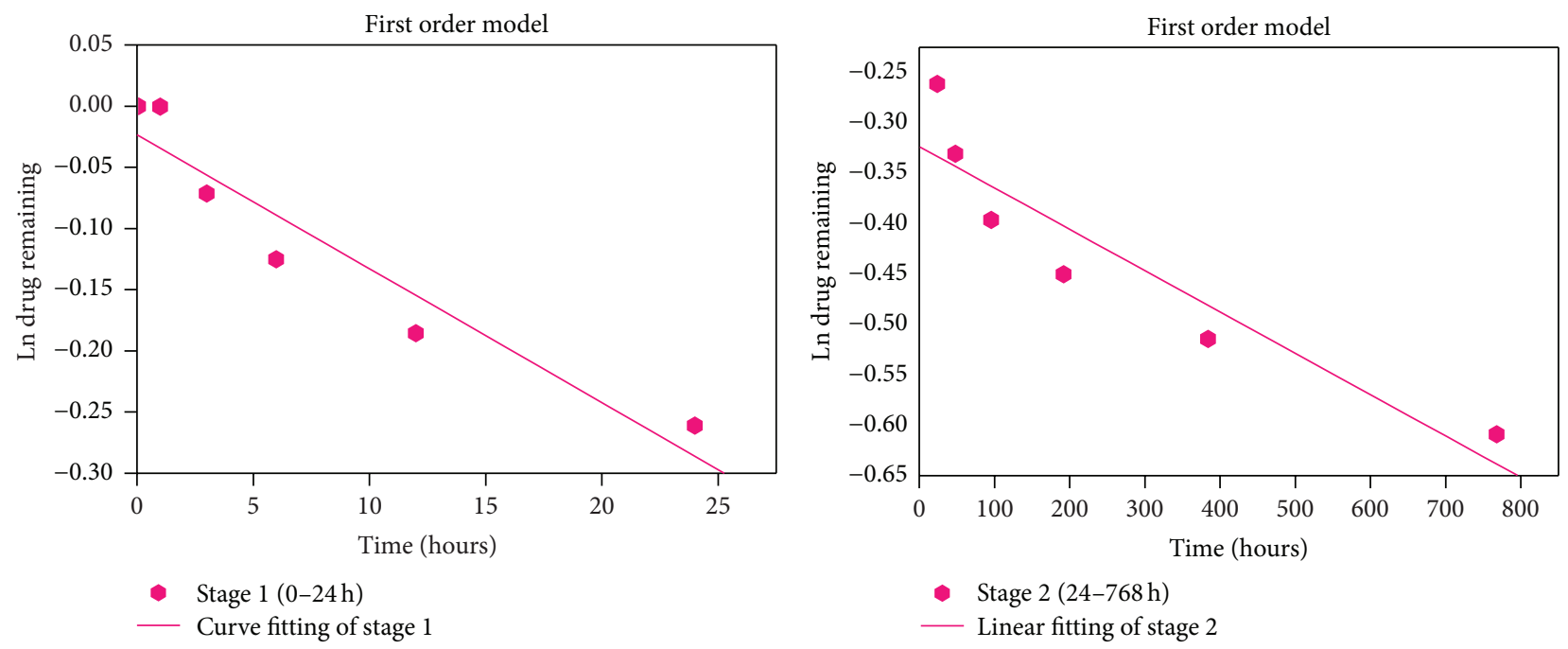

FIgURE 12: Application of the first-order model to both stages of 5-FU release profile from glass nanoparticles.

stage two obtained by applying this model were $10.95 \times 10^{-3}$ and $0.41 \times 10^{-3} \mathrm{~h}^{-1}$, respectively.

Modeling of drug release profile using different mathematical models in this work revealed that the quality of fit for stage one was always enhanced compared to that for stage two; that is, $R_{C}$ is higher for stage one than stage two. This observation was in agreement with previous studies, as they had reported that significant deviation was possible beyond 50\% release [26, 28]. Regression analyses using different models showed that drug release profile from glass nanoparticles during stages one and two was best expressed by Baker-Lonsdale and Higuchi models as the curve fitting of release profile showed higher linearity than the other models. However, other models used in this work were also applicable as they showed fairly good linearity with release profile with relatively high correlation coefficients especially during stage one.

In brief, the major advantages of using bioactive glass nanoparticles as a controlled delivery system for 5-FU were the following:

(i) Bioactive glass nanoparticles that could be prepared on a large scale.

(ii) Degradability of these nanoparticles to a nontoxic product and thus no need for a second surgery to remove these particles from body.

(iii) The simplicity of drug loading method, which could allow modulation of drug release rate according to patient need by using different drug concentrations during loading stage.

(iv) Being able to provide a large concentration of drug molecules (burst release) during the first day after tumor resection, which could help killing any remaining of tumor cells.

(v) Drug-loaded nanoparticles that were able to provide a sustained release of therapeutic doses of 5-FU for long duration time as compared with other systems in the literature, which could prevent tumor recurrence after resection.

(vi) Biocompatibility, bioactivity, and ability to stimulate bone regeneration.

\section{Conclusions}

Bioactive glass nanoparticles were prepared and used for sustained 5-FU delivery. They were characterized by TEM, DTA, TGA, and FT-IR. In addition, surface area and porosity $\%$ were measured by high-speed gas sorption analyzer and mercury intrusion porosimetry technique, respectively. Moreover, SEM and TF-XRD were used to confirm the in vitro bioactivity of glass disks prepared from these nanoparticles in simulated body fluid. Results of this study showed that 5 -FU is successfully loaded onto glass nanoparticles. The in vitro drug release experiment indicated that bioactive glass 
nanoparticles could serve as long-term local delivery vehicles for sustained 5-FU release. The application of different mathematical models indicated that 5-FU was released by diffusion controlled mechanism and suggested that its release profile was dependent on glass particles dissolution, changes of surface area as well as diameter of glass particles, and concentration of loaded drug.

\section{Conflict of Interests}

There is no conflict of interests regarding the publication of this paper.

\section{References}

[1] D. B. Longley, D. P. Harkin, and P. G. Johnston, "5-Fluorouracil: mechanisms of action and clinical strategies," Nature Reviews Cancer, vol. 3, no. 5, pp. 330-338, 2003.

[2] J. L. Grem, "5-Fluorinated pyrimidine," in Cancer Chemotherapy and Biotherapy. Principles and Practice, B. A. Chabner and D. L. Longo, Eds., pp. 149-210, Lippincott-Raven, Philadelphia, $\mathrm{Pa}$, USA, 1996.

[3] K. Ciftci, H. S. Kas, A. A. Hincal, T. M. Ercan, O. Güven, and S. Ruacan, "In vitro and in vivo evaluation of PLAGA (50/50) microspheres containing 5 -fluorouracil prepared by a solvent evaporation method," International Journal of Pharmaceutics, vol. 131, no. 1, pp. 73-82, 1996.

[4] M. H. Pérez, C. Zinutti, A. Lamprecht et al., "The preparation and evaluation of poly( $\varepsilon$-caprolactone) microparticles containing both a lipophilic and a hydrophilic drug," Journal of Controlled Release, vol. 65, no. 3, pp. 429-438, 2000.

[5] R. T. Liggins, S. D’Amours, J. S. Demetrick, L. S. MacHan, and H. M. Burt, "Paclitaxel loaded poly(L-lactic acid) microspheres for the prevention of intraperitoneal carcinomatosis after a surgical repair and tumor cell spill," Biomaterials, vol. 21, no. 19, pp. 19591969, 2000.

[6] Y. Zhang, J. Li, M. Lang, X. Tang, L. Li, and X. Shen, "Folatefunctionalized nanoparticles for controlled 5-Fluorouracil delivery," Journal of Colloid and Interface Science, vol. 354, no. 1, pp. 202-209, 2011.

[7] H. Zhu, H. Chen, X. Zeng et al., "Co-delivery of chemotherapeutic drugs with vitamin E TPGS by porous PLGA nanoparticles for enhanced chemotherapy against multi-drug resistance," Biomaterials, vol. 35, no. 7, pp. 2391-2400, 2014.

[8] P. Sepulveda, J. R. Jones, and L. L. Hench, "Bioactive solgel foams for tissue repair," Journal of Biomedical Materials Research, vol. 59, no. 2, pp. 340-348, 2002.

[9] P. Saravanapavan, J. R. Jones, R. S. Pryce, and L. L. Hench, "Bioactivity of gel-glass powders in the $\mathrm{CaO}-\mathrm{SiO}_{2}$ system: a comparison with ternary $\left(\mathrm{CaO}-\mathrm{P}_{2} \mathrm{O}_{5}-\mathrm{SiO}_{2}\right)$ and quaternary glasses $\left(\mathrm{SiO}_{2}-\mathrm{CaO}-\mathrm{P}_{2} \mathrm{O}_{5}-\mathrm{Na}_{2} \mathrm{O}\right)$," Journal of Biomedical Materials Research Part A, vol. 66, no. 1, pp. 110-119, 2003.

[10] R. L. Siqueira, O. Peitl, and E. D. Zanotto, "Gel-derived $\mathrm{SiO}_{2}$ $\mathrm{CaO}-\mathrm{Na}_{2} \mathrm{O}-\mathrm{P}_{2} \mathrm{O}_{5}$ bioactive powders: synthesis and in vitro bioactivity," Materials Science and Engineering C, vol. 31, no. 5, pp. 983-991, 2011.

[11] R. Li, A. E. Clark, and L. L. Hench, "An investigation of bioactive glass powders by sol-gel processing," Journal of Applied Biomaterials, vol. 2, no. 4, pp. 231-239, 1991.

[12] I. A. Silver, J. Deas, and M. Erecińska, "Interactions of bioactive glasses with osteoblasts in vitro: effects of 45S5 Bioglass, and
$58 \mathrm{~S}$ and $77 \mathrm{~S}$ bioactive glasses on metabolism, intracellular ion concentrations and cell viability," Biomaterials, vol. 22, no. 2, pp. 175-185, 2001.

[13] D. C. Greenspan, J. P. Zhong, and D. L. Wheeler, "Bioactivity and biodegradability: melt vs sol-gel derived bioglass in vitro and in vivo," in Proceedings of the 11th International Symposium on Ceramics in Medicine (Bioceramics '98), R. Z. LeGeros and J. P. LeGeros, Eds., p. 345, New York, NY, USA, November 1998.

[14] J. R. Jones, "Review of bioactive glass: from Hench to hybrids," Acta Biomaterialia, vol. 9, no. 1, pp. 4457-4486, 2013.

[15] A. A. Zadpoor, "Relationship between in vitro apatite-forming ability measured using simulated body fluid and in vivo bioactivity of biomaterials," Materials Science and Engineering C, vol. 35, no. 1, pp. 134-143, 2014.

[16] M. N. Rahaman, D. E. Day, B. Sonny Bal et al., "Bioactive glass in tissue engineering," Acta Biomaterialia, vol. 7, no. 6, pp. 23552373, 2011.

[17] G. Kaur, O. P. Pandey, K. Singh, D. Homa, B. Scott, and G. Pickrell, "A review of bioactive glasses: their structure, properties, fabrication and apatite formation," Journal of Biomedical Materials Research A, vol. 102, no. 1, pp. 254-274, 2014.

[18] A. M. El-Kady, A. F. Ali, and M. M. Farag, "Development, characterization, and in vitro bioactivity studies of sol-gel bioactive glass/poly(l-lactide) nanocomposite scaffolds," Materials Science and Engineering C, vol. 30, no. 1, pp. 120-131, 2010.

[19] A. M. El-Kady and A. F. Ali, "Fabrication and characterization of $\mathrm{ZnO}$ modified bioactive glass nanoparticles," Ceramics International, vol. 38, no. 2, pp. 1195-1204, 2012.

[20] W. Xia and J. Chang, "Preparation and characterization of nano-bioactive-glasses (NBG) by a quick alkali-mediated solgel method," Materials Letters, vol. 61, no. 14-15, pp. 3251-3253, 2007.

[21] M. Mačković, A. Hoppe, R. Detsch et al., "Bioactive glass (type 45S5) nanoparticles: in vitro reactivity on nanoscale and biocompatibility," Journal of Nanoparticle Research, vol. 14, no. 7, pp. 1-22, 2012.

[22] A. Hoppe, B. Sarker, R. Detsch et al., "In vitro reactivity of Srcontaining bioactive glass (type 1393) nanoparticles," Journal of Non-Crystalline Solids, vol. 387, pp. 41-46, 2014.

[23] A. M. El-Kady, A. F. Ali, R. A. Rizk, and M. M. Ahmed, "Synthesis, characterization and microbiological response of silver doped bioactive glass nanoparticles," Ceramics International, vol. 38, no. 1, pp. 177-188, 2012.

[24] A. M. El-Kady, R. A. Rizk, B. M. Abd El-Hady, M. W. Shafaa, and M. M. Ahmed, "Characterization, and antibacterial properties of novel silver releasing nanocomposite scaffolds fabricated by the gas foaming/salt-leaching technique," Journal of Genetic Engineering and Biotechnology, vol. 10, no. 2, pp. 229-238, 2012.

[25] N. Gargiulo, A. M. Cusano, F. Causa, D. Caputo, and P. A. Netti, "Silver-containing mesoporous bioactive glass with improved antibacterial properties," Journal of Materials Science: Materials in Medicine, vol. 24, no. 9, pp. 2129-2135, 2013.

[26] T. Higuchi, "Mechanism of sustained action medication: theoretical analysis of rate of release of solid drugs dispersed in solid matrices," Journal of Pharmaceutical Sciences, vol. 52, no. 12, pp. 1145-1149, 1963.

[27] P. L. Ritger and N. A. Peppas, "A simple equation for description of solute release I. Fickian and non-fickian release from nonswellable devices in the form of slabs, spheres, cylinders or discs," Journal of Controlled Release, vol. 5, no. 1, pp. 23-36, 1987. 
[28] S. Radin, T. Chen, and P. Ducheyne, "The controlled release of drugs from emulsified, sol gel processed silica microspheres," Biomaterials, vol. 30, no. 5, pp. 850-858, 2009.

[29] C. Gu, V. Le, M. Lang, and J. Liu, "Preparation of polysaccharide derivates chitosan-graft-poly( $\varepsilon$-caprolactone) amphiphilic copolymer micelles for 5-fluorouracil drug delivery," Colloids and Surfaces B: Biointerfaces, vol. 116, pp. 745-750, 2014.

[30] S. A. M. Abdel-Hameed, A. M. El-Kady, and M. A. Marzouk, "Magnetic glass ceramics for sustained 5-fluorouracil delivery: characterization and evaluation of drug release kinetics," Materials Science and Engineering C, vol. 44, pp. 293-309, 2014.

[31] T. Kokubo and H. Takadama, "How useful is SBF in predicting in vivo bone bioactivity?" Biomaterials, vol. 27, no. 15, pp. 29072915, 2006.

[32] I. Izquierdo-Barba, A. J. Salinas, and M. Vallet-Regí, “In vitro calcium phosphate layer formation on sol-gel glasses of the $\mathrm{CaO}-\mathrm{SiO}_{2}$ system," Journal of Biomedical Materials Research, vol. 47, no. 2, pp. 243-250, 1999.

[33] H. A. ElBatal, M. A. Azooz, E. M. A. Khalil, A. Soltan Monem, and Y. M. Hamdy, "Characterization of some bioglassceramics," Materials Chemistry and Physics, vol. 80, no. 3, pp. 599-609, 2003.

[34] J. Wong and C. A. Angell, Glass Structure by Spectroscopy, Marcel Dekker, New York, NY, USA, 1976.

[35] C. I. Merzbacher and W. B. White, "The structure of alkaline earth aluminosilicate glasses as determined by vibrational spectroscopy," Journal of Non-Crystalline Solids, vol. 130, no. 1, pp. 18-34, 1991.

[36] C. Y. Kim, A. E. Clark, and L. L. Hench, "Early stages of calcium-phosphate layer formation in bioglasses," Journal of Non-Crystalline Solids, vol. 113, no. 2-3, pp. 195-202, 1989.

[37] M. R. T. Filgueiras, G. P. LaTorre, and L. L. Hench, "Solution effects on the surface reactions of three bioactive glass compositions," Journal of Biomedical Materials Research, vol. 27, no. 12, pp. 1485-1493, 1993.

[38] F. H. ElBatal and A. ElKheshen, "Preparation and characterization of some substituted bioglasses and their ceramic derivatives from the system $\mathrm{SiO}_{2}-\mathrm{Na}_{2} \mathrm{O}-\mathrm{CaO}-\mathrm{P}_{2} \mathrm{O}_{5}$ and effect of gamma irradiation," Materials Chemistry and Physics, vol. 110, no. 2-3, pp. 352-362, 2008.

[39] N. J. Coleman and L. L. Hench, "Gel-derived mesoporous silica reference material for surface analysis by gas sorption. 1. Textural features," Ceramics International, vol. 26, no. 2, pp. 171178, 2000.

[40] L. L. Hench, "Bioceramics: from concept to clinic," Journal of the American Ceramic Society, vol. 74, no. 7, pp. 1487-1510, 1991.

[41] C. Santos, M. A. Martins, R.-P. Franke, M. M. Almeida, and M. E. V. Costa, "Calcium phosphate granules for use as a 5fluorouracil delivery system," Ceramics International, vol. 35, no. 4, pp. 1587-1594, 2009.

[42] C.-Y. Yu, X.-C. Zhang, F.-Z. Zhou, X.-Z. Zhang, S.-X. Cheng, and R.-X. Zhuo, "Sustained release of antineoplastic drugs from chitosan-reinforced alginate microparticle drug delivery systems," International Journal of Pharmaceutics, vol. 357, no. 12, pp. 15-21, 2008.

[43] L. Zhu, J. Ma, N. Jia, Y. Zhao, and H. Shen, "Chitosancoated magnetic nanoparticles as carriers of 5-Fluorouracil: preparation, characterization and cytotoxicity studies," Colloids and Surfaces B: Biointerfaces, vol. 68, no. 1, pp. 1-6, 2009.

[44] V. R. Babu, M. Sairam, K. M. Hosamani, and T. M. Aminabhavi, "Development of 5-fluorouracil loaded poly(acrylamide-comethylmethacrylate) novel core-shell microspheres: in vitro release studies," International Journal of Pharmaceutics, vol. 325, no. 1-2, pp. 55-62, 2006.

[45] F. Bellezza, A. Alberani, M. Nocchetti, V. Marsili, and A. Cipiciani, "Intercalation of 5-fluorouracil into $\mathrm{ZnAl}$ hydrotalcitelike nanoparticles: preparation, characterization and drug release," Applied Clay Science, vol. 101, pp. 320-326, 2014.

[46] N. Ashwanikumar, N. A. Kumar, S. A. Nair, and G. S. V. Kumar, "Dual drug delivery of 5-fluorouracil (5-FU) and methotrexate (MTX) through random copolymeric nanomicelles of PLGA and polyethylenimine demonstrating enhanced cell uptake and cytotoxicity," Colloids and Surfaces B: Biointerfaces, vol. 122, pp. 520-528, 2014. 

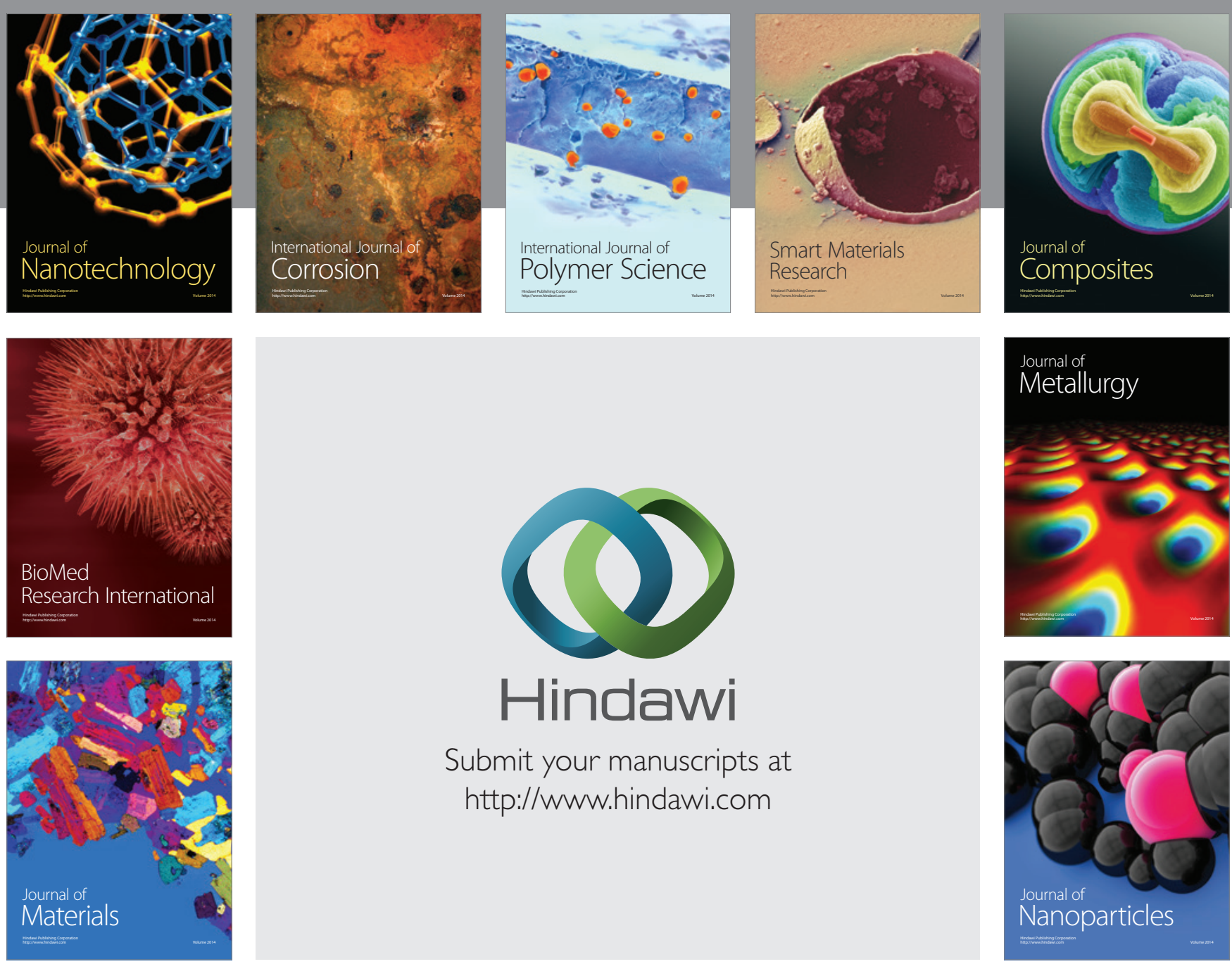

Submit your manuscripts at http://www.hindawi.com
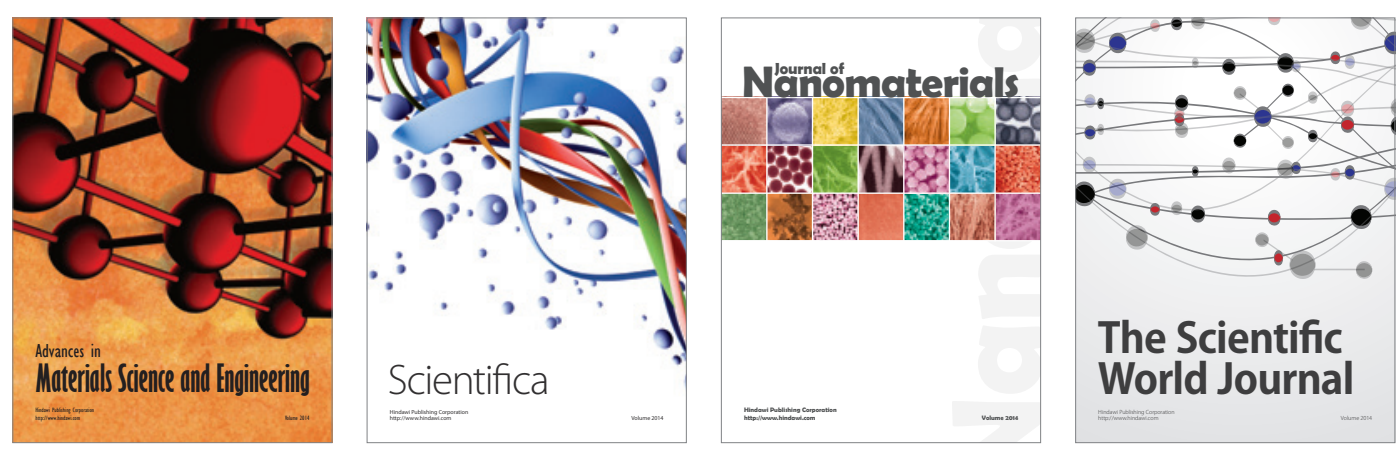

\section{The Scientific World Journal}
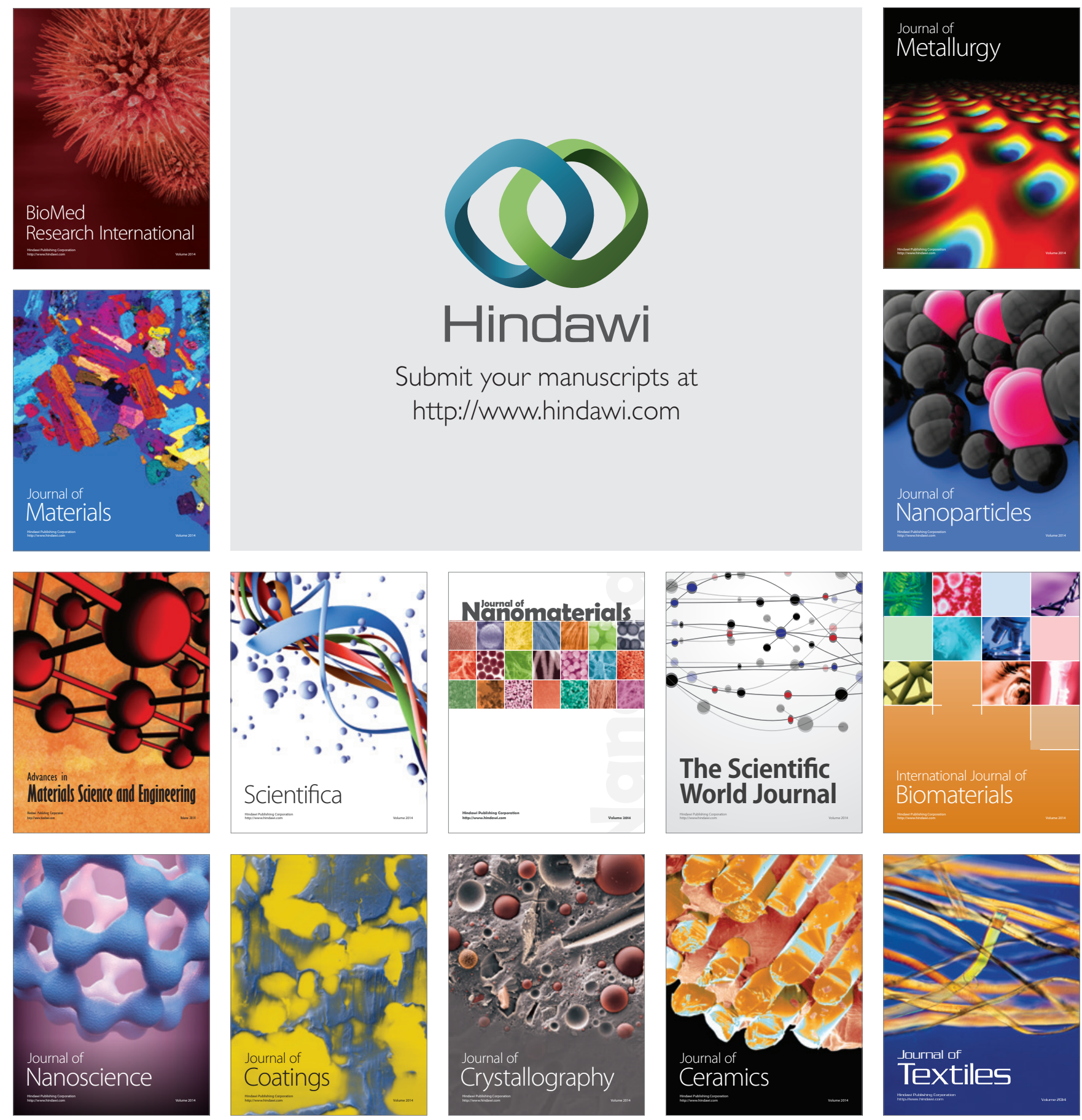